\title{
Impact of Operator on Determining Functional Parameters of Nuclear Medicine Procedures
}

\author{
A.M. Mohammed $^{a, b}$ S.Y. Naddaf ${ }^{a, b}$ F.S. Mahdi ${ }^{b}$ Q.I. Al-Mutawa ${ }^{b}$ \\ H.A. Al-Dossary ${ }^{b}$ A.H. Elgazzar ${ }^{a, b}$ \\ a Department of Nuclear Medicine, Faculty of Medicine, Kuwait University, and \\ ${ }^{\mathrm{b}}$ Mubarak Al-Kaber Hospital, Kuwait, Kuwait
}

\section{Key Words}

Operator variability · Nuclear medicine, functional

parameters

\begin{abstract}
Objective: The study was designed to assess the significance of the interoperator variability in the estimation of functional parameters for four nuclear medicine procedures. Materials and Methods: Three nuclear medicine technologists with varying years of experience processed the following randomly selected 20 cases with diverse functions of each study type: renography, renal cortical scans, myocardial perfusion gated single-photon emission computed tomography (MP-GSPECT) and gated blood pool ventriculography (GBPV). The technologists used the same standard processing routines and were blinded to the results of each other. The means of the values and the means of differences calculated case by case were statistically analyzed by one-way ANOVA. The values were further analyzed using Pearson correlation. Results: The range of the mean values and standard deviation of relative renal function obtained by the three technologists were $50.65 \pm 3.9$ to $50.92 \pm 4.4 \%$ for renography, $51.43 \pm 8.4$ to $51.55 \pm 8.8 \%$ for renal cortical scans, $57.40 \pm 14.3$ to $58.30 \pm 14.9 \%$ for left ventricular ejection fraction from MP-GSPECT and $54.80 \pm 12.8$ to
\end{abstract}

$55.10 \pm 13.1 \%$ for GBPV. The difference was not statistically significant, $p>0.9$. The values showed a high correlation of more than 0.95 . Calculated case by case, the mean of differences \pm SD was found to range from 0.42 $\pm 0.36 \%$ in renal cortical scans to $1.35 \pm 0.87 \%$ in MPGSPECT with a maximum difference of $4.00 \%$. The difference was not statistically significant, $p>0.19$. Conclusion: The estimated functional parameters were reproducible and operator independent as long as the standard processing instructions were followed.

Copyright $\odot 2006$ S. Karger AG, Basel

\section{Introduction}

Several nuclear medicine procedures involve estimation of functional parameters of the organ or system under investigation. Renography, renal cortical scans, electrocardiographically gated myocardial perfusion singlephoton emission computed tomography (MP-GSPECT) and gated blood pool ventriculography (GBPV) are examples of such procedures. The functional parameters provided by renography include relative uptake ratios (split renal function, $S R F$ ) and $t_{1 / 2}$ values of the uptake and excretion phases, while renal cortical scans provide mostly an estimation of the SRF. The functional parameters provided by cardiac procedures include left ventricular

\section{KARGER}

Fax +4161306 1234 E-Mail karger@karger.ch www.karger.com
(C) 2006 S. Karger AG, Basel

$1011-7571 / 06 / 0153-0209 \$ 23.50 / 0$

Accessible online at:

www.karger.com/mpp
Ahmed M. Mohammed

Department of Nuclear Medicine, Faculty of Medicine, Kuwait University PO Box 24923, Safat

13110 Kuwait (Kuwait)

Tel. +965 498 6412, Fax +965 533 8936, E-Mail ahmedm@hsc.edu.kw 
Fig. 1. Examples of drawn regions of interest around the kidneys in renography (a), renal cortical scan (b) and GBPV (d), and an example of adjusted limits and orientations in MP-GSPECT (c).
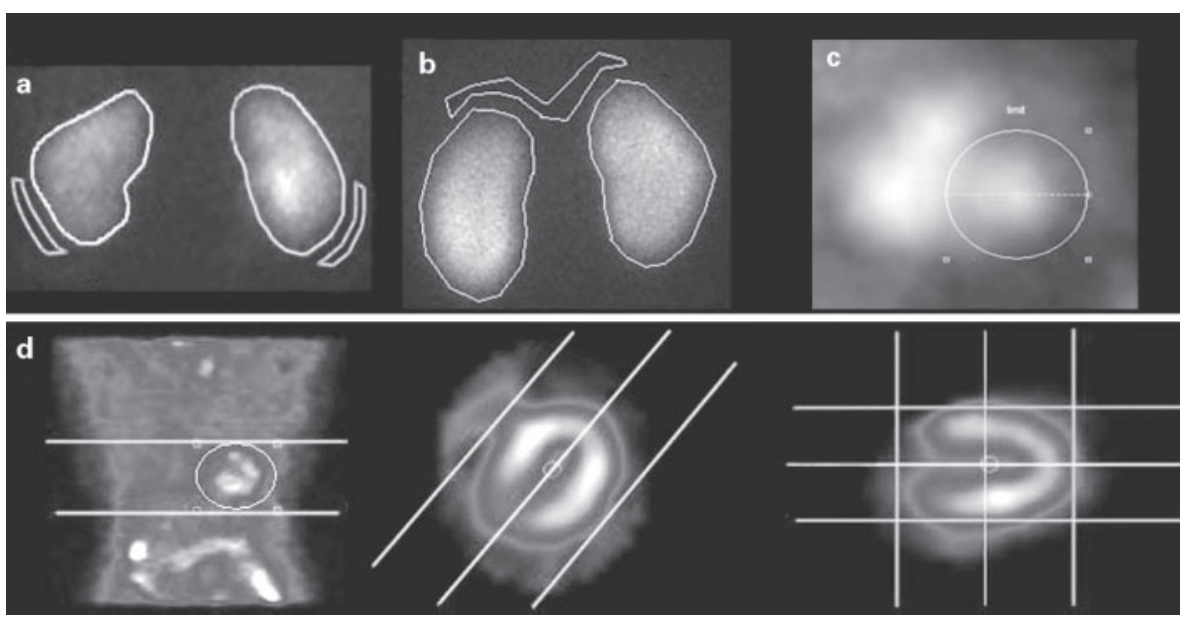

ejection fraction (LVEF) and end-diastolic, end-systolic and stroke volumes [1].

The process by which the values for such parameters are estimated is automatic, semiautomatic or manual. Although some centers providing nuclear medicine service use intradepartmentally developed automated processing softwares, most of the commercially used processing packages in routine clinical practice are semiautomated. Semiautomatic processing involves manual drawing of a wide region around the organ of interest. The drawn region is then used to automatically detect the contour of the organ located within that region, common in processing GBPV. Processing renal studies, on the other hand, commonly involves drawing regions that carefully outline the contour of the kidneys. Semiautomated processing may also involve selection of proper limits and axis orientation of the reconstructed slices as in processing of cardiac SPECT studies.

Although image processing is usually simple, practical and user friendly [2-6] and the obtained values correlate well with other standard imaging modalities or laboratory findings [7-10], different nuclear medicine technologists would process the same data and provide different estimations of the functional parameters. The significance of the estimated values and their possible impact on making a diagnosis or modifying a patient's management requires that the difference in estimation be insignificant.

The objective of this study was to assess the significance of the interoperator variability in estimating the functional parameters of relative renal function and LVEF.

\section{Materials and Methods}

Three nuclear medicine technologists (designated $\mathrm{O} 1, \mathrm{O} 2$ and O3) with varying years of experience in general nuclear medicine were recruited for the study. The technologists were asked to process the same randomly selected 20 cases of each study type - renography, renal cortical scans, MP-GSPECT and GBPV - using the processing programs provided by the system manufacturer (Xeleres Workstation ${ }^{\circledR}$ version 1.06, GE Medical Systems). The programs included renal analysis, renal dimercaptosuccinic acid uptake analysis, quantitative gated SPECT and ejection fraction analysis, respectively. The technologists used the same standard instructions for processing the studies. The instructions included drawing regions around the organs of interest in renography, renal cortical scans and GBPV, and setting reconstruction limits and orientations in MP-GSPECT (fig. 1). The technologists were also blinded to the results obtained by each other. The functional parameters obtained included percent SRF from renography and renal cortical scans, and percent LVEF from myocardial perfusion MP-GSPECT and GBPV. One-way ANOVA was used to statistically analyze the means of the estimated values of the functional parameters for significant difference among the three technologists or groups. The values were also correlated using Pearson correlation and plotted using scatter graphs. Moreover, the differences between every two values were calculated and then analyzed by one-way ANOVA to analyze the differences between the technologists from case to case. The values were expressed as means \pm standard deviation (SD). p values of less than 0.05 were considered statistically significant. All statistical analyses were performed using SPSS for Windows ${ }^{\circledR}$ version 12.0.

\section{Results}

The functional parameters obtained by each technologist are listed in tables 1 and 2. In table 1, the SRF of the right kidney was recorded because the measured renal function of any kidney in renography or renal cortical 
Table 1. Individual values of percent SRF for each technologist

\begin{tabular}{|c|c|c|c|c|c|c|}
\hline & \multicolumn{3}{|c|}{ Renography } & \multicolumn{3}{|c|}{ Renal cortical scan } \\
\hline & $\mathrm{O} 1$ & $\mathrm{O} 2$ & $\mathrm{O} 3$ & $\mathrm{O} 1$ & $\mathrm{O} 2$ & $\mathrm{O} 3$ \\
\hline 1 & 54.60 & 54.50 & 53.00 & 48.90 & 49.70 & 49.10 \\
\hline 2 & 48.00 & 50.10 & 49.90 & 49.30 & 49.10 & 49.30 \\
\hline 3 & 50.70 & 49.00 & 50.50 & 48.80 & 49.00 & 49.10 \\
\hline 4 & 58.60 & 57.10 & 59.10 & 84.40 & 85.40 & 83.70 \\
\hline 5 & 50.00 & 52.10 & 52.80 & 52.00 & 53.10 & 53.50 \\
\hline 6 & 62.70 & 60.00 & 61.60 & 47.90 & 47.20 & 47.30 \\
\hline 7 & 49.00 & 49.10 & 48.90 & 47.40 & 47.00 & 46.60 \\
\hline 8 & 48.10 & 49.10 & 49.50 & 38.40 & 38.10 & 38.80 \\
\hline 9 & 47.00 & 45.90 & 46.80 & 54.40 & 53.90 & 54.10 \\
\hline 10 & 42.90 & 44.20 & 41.50 & 49.90 & 49.80 & 50.20 \\
\hline 11 & 47.30 & 46.00 & 48.00 & 49.70 & 48.90 & 49.30 \\
\hline 12 & 52.50 & 50.90 & 53.00 & 51.10 & 51.30 & 50.90 \\
\hline 13 & 51.00 & 50.90 & 50.50 & 45.70 & 45.60 & 46.10 \\
\hline 14 & 50.90 & 51.50 & 51.30 & 51.80 & 51.70 & 51.70 \\
\hline 15 & 48.40 & 48.10 & 48.50 & 55.10 & 55.50 & 55.00 \\
\hline 16 & 47.60 & 47.00 & 46.10 & 52.60 & 53.10 & 52.60 \\
\hline 17 & 50.70 & 50.40 & 50.80 & 54.00 & 53.40 & 53.70 \\
\hline 18 & 54.40 & 53.00 & 52.40 & 47.30 & 47.10 & 47.10 \\
\hline 19 & 54.00 & 55.50 & 55.40 & 52.90 & 52.70 & 52.10 \\
\hline 20 & 49.50 & 48.70 & 48.80 & 49.20 & 49.50 & 48.40 \\
\hline
\end{tabular}

Table 2. Individual values of percent $L V E F$ for each technologist

\begin{tabular}{|c|c|c|c|c|c|c|}
\hline & \multicolumn{3}{|c|}{ MP-GSPECT } & \multicolumn{3}{|c|}{ Gated blood pool } \\
\hline & O1 & $\mathrm{O} 2$ & $\mathrm{O} 3$ & $\mathrm{O} 1$ & $\mathrm{O} 2$ & $\mathrm{O} 3$ \\
\hline 1 & 57.00 & 55.00 & 57.00 & 60.00 & 61.00 & 61.00 \\
\hline 2 & 45.00 & 43.00 & 44.00 & 46.00 & 45.00 & 43.00 \\
\hline 3 & 69.00 & 69.00 & 66.00 & 41.00 & 41.00 & 43.00 \\
\hline 4 & 63.00 & 62.00 & 61.00 & 64.00 & 63.00 & 65.00 \\
\hline 5 & 63.00 & 64.00 & 64.00 & 65.00 & 62.00 & 61.00 \\
\hline 6 & 83.00 & 83.00 & 82.00 & 47.00 & 46.00 & 47.00 \\
\hline 7 & 80.00 & 78.00 & 76.00 & 26.00 & 28.00 & 27.00 \\
\hline 8 & 58.00 & 57.00 & 56.00 & 54.00 & 54.00 & 52.00 \\
\hline 9 & 58.00 & 58.00 & 55.00 & 61.00 & 59.00 & 61.00 \\
\hline 10 & 42.00 & 43.00 & 41.00 & 66.00 & 63.00 & 65.00 \\
\hline 11 & 50.00 & 49.00 & 51.00 & 66.00 & 67.00 & 65.00 \\
\hline 12 & 26.00 & 26.00 & 27.00 & 27.00 & 27.00 & 28.00 \\
\hline 13 & 51.00 & 50.00 & 51.00 & 70.00 & 72.00 & 71.00 \\
\hline 14 & 38.00 & 37.00 & 38.00 & 67.00 & 66.00 & 67.00 \\
\hline 15 & 70.00 & 71.00 & 70.00 & 62.00 & 63.00 & 62.00 \\
\hline 16 & 56.00 & 56.00 & 56.00 & 71.00 & 71.00 & 72.00 \\
\hline 17 & 69.00 & 68.00 & 66.00 & 59.00 & 58.00 & 59.00 \\
\hline 18 & 80.00 & 79.00 & 80.00 & 45.00 & 45.00 & 46.00 \\
\hline 19 & 65.00 & 65.00 & 63.00 & 53.00 & 53.00 & 52.00 \\
\hline 20 & 43.00 & 44.00 & 44.00 & 52.00 & 52.00 & 52.00 \\
\hline
\end{tabular}

Table 3. Mean values and SD in the estimated values of functional parameters obtained by the three nuclear medicine technologists

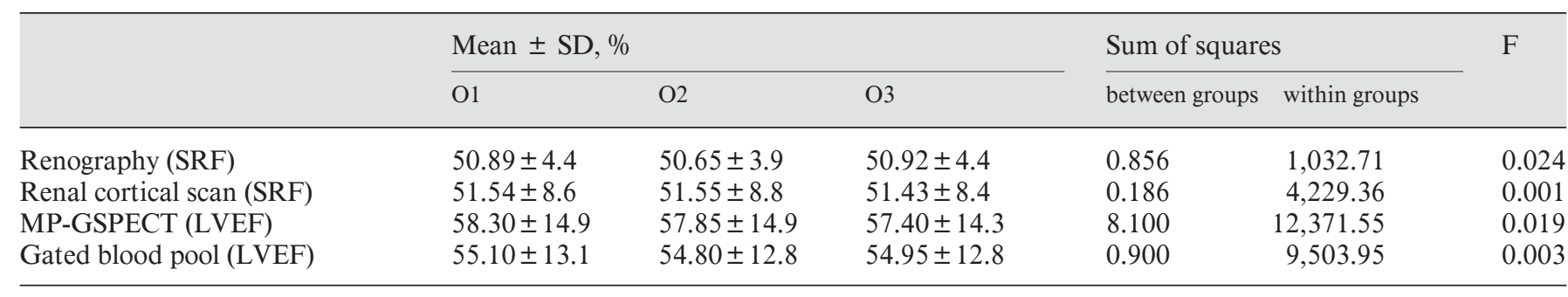

scans is relative to the total renal function. The mean \pm $\mathrm{SD}$ in the estimated values of the SRF obtained from renography and renal cortical scans provided by the three nuclear medicine technologists ranged from $50.65 \pm 3.9$ to $50.92 \pm 4.4 \%$, and $51.34 \pm 8.4$ to $51.55 \pm 8.8 \%$, respectively (table 3 ). The mean values \pm SD in the estimated LVEF obtained from myocardial perfusion MPGSPECT and GBPV ranged from $57.40 \pm 14.3$ to 58.30 $\pm 14.9 \%$, and $54.80 \pm 12.8$ to $55.10 \pm 13.1 \%$, respectively. The mean values, however, showed no statistically significant difference, $p>0.9$. Pearson correlation between any two technologists ( $\mathrm{O} 1$ and $\mathrm{O} 2, \mathrm{O} 1$ and $\mathrm{O} 3$, and $\mathrm{O} 2$ and $\mathrm{O} 3$ ) was more than 0.950 for all the four study types with $p$ values of less than 0.001 (table 4 ). The values
Table 4. Pearson correlation between the values obtained by the three technologists

\begin{tabular}{lll}
\hline & O2 & O3 \\
\hline $\begin{array}{lll}\text { Renography } \\
\quad \text { O1 }\end{array}$ & 0.955 & 0.960 \\
O2 & & 0.964 \\
Renal cortical scan & & \\
$\quad$ O1 & 0.999 & 0.998 \\
O2 & & 0.999 \\
MP-GSPECT & & \\
$\quad$ O1 & 0.998 & 0.996 \\
O2 & & 0.995 \\
Gated blood pool & & \\
$\quad$ O1 & 0.995 & 0.994 \\
O2 & & 0.994 \\
\hline
\end{tabular}




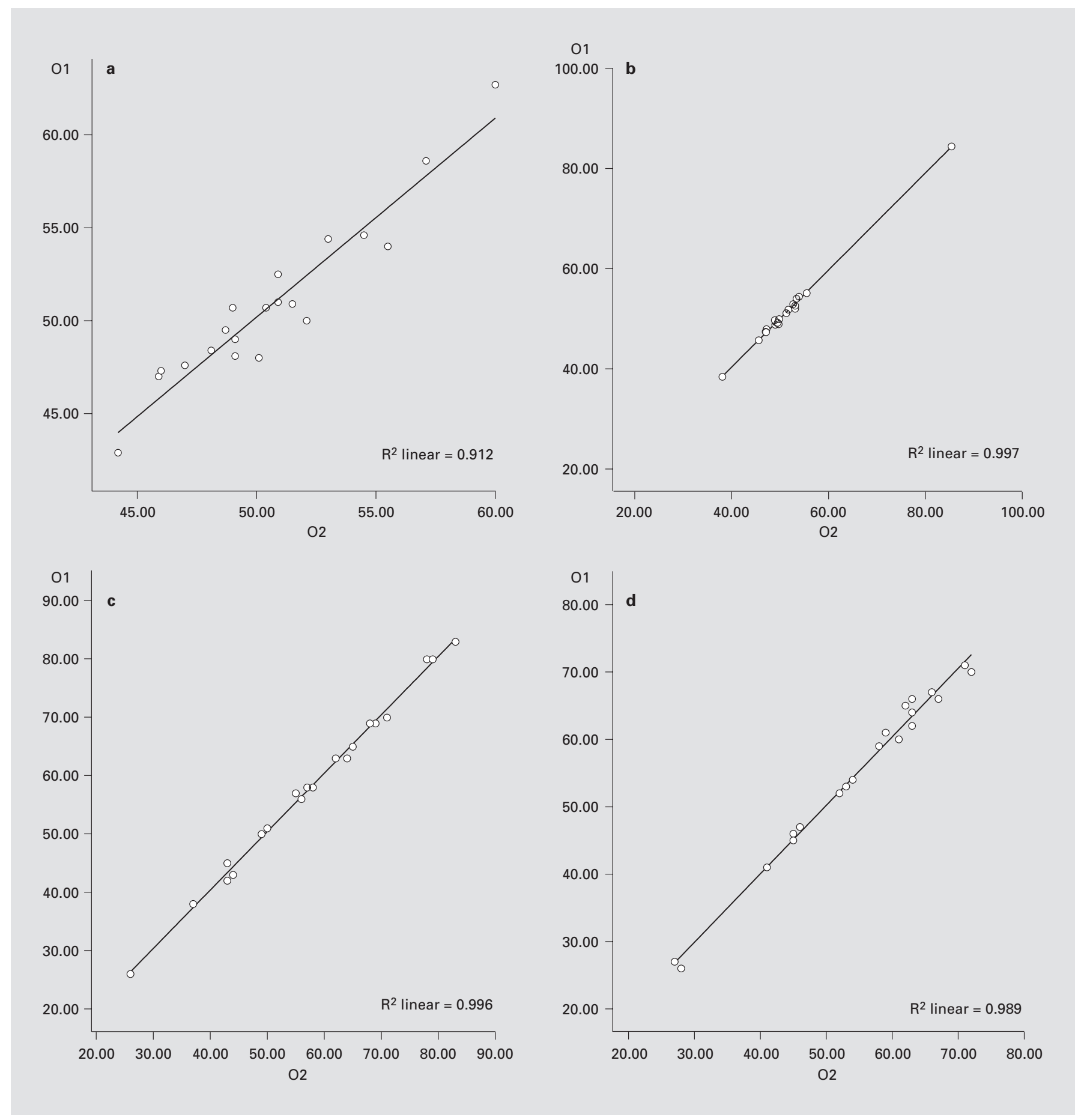

Fig. 2. Scattergrams correlating the values estimated by the different technologists.

when plotted using scattergraphs fell roughly in an ellipse and showed a linear relationship (fig. 2).

To assess the interoperator variability in the estimation of the functional parameters, the differences in the estimated values from case to case were analyzed. The mean $\pm \mathrm{SD}$ in the difference values of the SRF obtained from renography and renal cortical scans ranged from $0.94 \pm 0.80$ to $1.11 \pm 0.74 \%$, and $0.42 \pm 0.36$ to 0.45 
Table 5. Mean difference \pm SD in estimated values of functional parameters obtained by the three nuclear medicine technologists

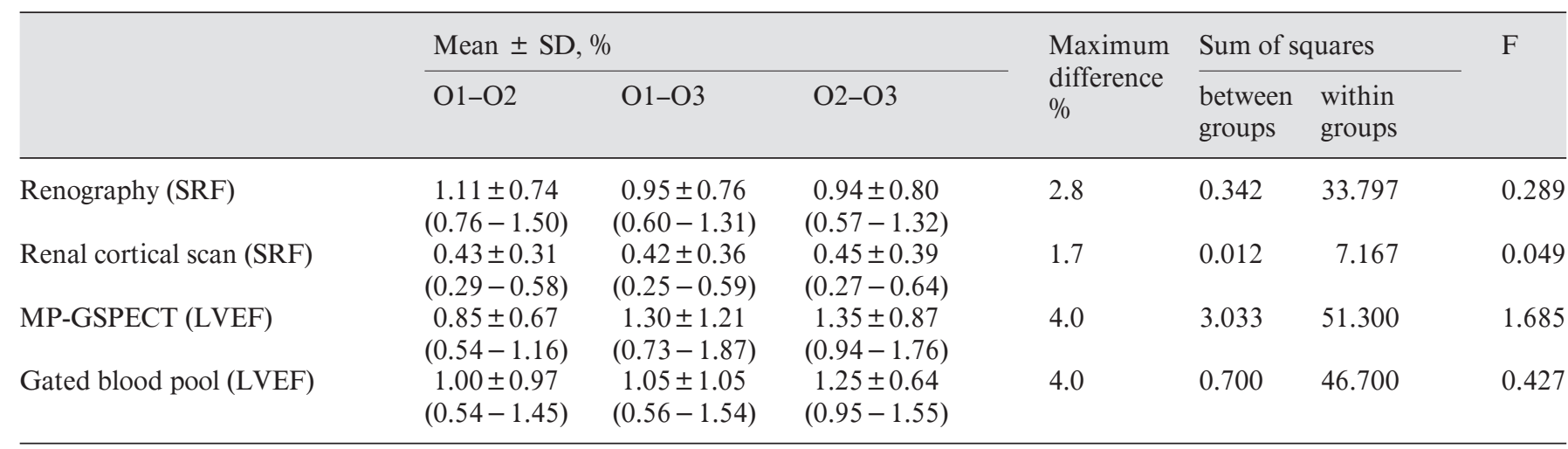

Figures in parentheses indicate $95 \%$ confidence intervals.

$\pm 0.39 \%$, respectively (table 5 ). The mean values $\pm \mathrm{SD}$ in the estimated LVEF obtained from myocardial perfusion MP-GSPECT and GBPV ranged from $0.85 \pm 0.67$ to $1.35 \pm 0.87 \%$, and $1.00 \pm 0.97$ to $1.25 \pm 0.64 \%$, respectively, with a maximum difference of $4.00 \%$. The mean values showed no statistically significant difference, $p>0.19$. This indicated insignificant interoperator variability in the estimation of the functional parameters obtained from the four nuclear medicine procedures.

\section{Discussion}

In contrast to some studies, which have reported significant variations [11-13], this study did not show any statistically significant difference in the estimated values from manually drawn reigions of interest among the three experienced technologists, indicating that the nuclear medicine procedures studied are reproducible and operator independent. This may be because the commercial packages for image processing have become more advanced and easy to use and the technologists more familiar and skillful in digital image processing. Understanding the effect of region manipulation on quantitative results may also account in part for such a finding.

The study also shows that the difference in estimated values is less than 5\% and is more in LVEF than in SRF (4.0 vs. $2.8 \%$ ). However, this range of difference was of no clinical significance in the processed cases since there was no single case that showed normal values by one technologist and abnormal values by another one. Nevertheless, both the nuclear medicine physician and the referring physician should be aware of this reported range when following up patients or when the values are at the borderline between normal and abnormal states. The results also indicate that reprocessing of the same study by another technologist would result in a value that is, if different, $\pm 5 \%$ of the one previously estimated, thus making reprocessing unnecessary. This is particularly true when the case is not complicated and permits implication of the same standard processing instructions.

\section{Conclusion}

As long as experienced nuclear medicine technologists follow the same standard processing instructions, the estimated values of the functional parameters provided by these nuclear medicine procedures are reproducible and operator independent. 


\section{References}

1 Cullom SJ, Case JA, Bateman MD: Electrocardiographically gated myocardial perfusion SPECT: technical principles and quality control considerations. J Nucl Cardiol 1998;5: 418-425.

-2 Germano G, Kiat H, Kavanagh PB, Moriel M, Mazzanti M, Su HT, Van Train KF, Berman DS: Automatic quantification of ejection fraction from gated myocardial perfusion SPECT. J Nucl Med 1995;36:2138-2147.

>3 Germano G, Erel J, Lewin H, Kavanagh PB, Berman DS: Automatic quantitation of regional myocardial wall motion and thickening from gated technetium-99m sestamibi myocardial perfusion single-photon emission computed tomography. J Am Coll Cardiol 1997;30: 1360-1367.

4 DePuey EG, Nichols K, Dobrinsky C: Left ventricular ejection fraction assessed from technetium-99m-sestamibi SPECT. J Nucl Med 1993;34:1871-1876.

5 Faber TL, Cooke CD, Folks RD, Vansant JP, Nichols KJ, DePuey EG, Pettigrew RI, Garcia EV: Left ventricular function and perfusion from gated perfusion images: an integrated method. J Nucl Med 1999;40:650-659.
-6 Everaert H, Franken PR, Flamen P, Goris M, Momen A, Bossuyt A: Left ventricular ejection fraction from gated SPECT myocardial perfusion studies: a method based on the radial distribution of count rate density across the myocardial wall. Eur J Nucl Med 1996;23: 1628-1633.

7 Tadamura E, Kudoh T, Motooka M, Inubushi M, Shirakawa S, Hattori N, Okada T, Matsuda T, Koshiji T, Nishimura K, Matsuda K, Konishi J: Assessment of regional and global left ventricular function by reinjection T1-201 and rest Tc-99m sestamibi ECG-gated SPECT: comparison with three-dimensional magnetic resonance imaging. J Am Coll Cardiol 1999; 33:991-997.

$>8$ Nichols K, Tamis J, DePuey EG, Mieres J, Malhotra S, Rozanski A: Relationship of gated SPECT ventricular function parameters to angiographic measurements. J Nucl Cardiol 1998;5:295-303.
$>9$ Cwajg E, Cwajg J, He ZX, Hwang WS, Keng F, Nagueh SF, Verani MS: Gated myocardial perfusion tomography for the assessment of left ventricular function and volumes: comparison with echocardiography. J Nucl Med 1999; 40:1857-1865.

10 Kondo C, Fukushima K, Kusakabe K: Measurement of left ventricular volumes and ejection fraction by quantitative gated SPECT, contrast ventriculography and magnetic resonance imaging: a meta-analysis. Eur J Nucl Med Mol Imaging 2003;30:851-858.

11 White DR, Houston AS, Sampson WF, Wilkins GP: Intra- and interoperator variations in region-of-interest drawing and their effect on the measurement of glomerular filtration rates. Clin Nucl Med 1999;24:177-181.

12 Jackson PC, Jones M, Brimble CE, Hart J: The reduction of inter- and intra-observer variability for defining regions of interest in nuclear medicine. Eur J Nucl Med 1985;11:186-189.

-13 Tomaru Y, Inoue T, Oriuchi N, Takahashi K, Endo K: Semi-automated renal region of interest selection method using the double-threshold technique: inter-operator variability in quantitating ${ }^{99 \mathrm{~m}}$ Tc-MAG3 renal uptake. Eur J Nucl Med 1998;25:55-59. 